practices may change over time, which would affect the IQ scores.

Shaw and colleagues find no significant correlation between cortical thickness and intelligence in their data from young children. Yet they cite a study of adults by $\mathrm{McDaniel}^{2}$ that reports a modest correlation of 0.3 between intelligence and the total volume of the brain. The reason for the different results could be that the relevant factor is the total area of the cortex rather than its thickness, but it turns out that this is probably not the case. As the children were followed up, the nature of the relationship changed. In young children, the correlation tended to be negative, but in late childhood, around the age of ten, it was positive.

The authors illustrate this point by plotting continuous curves of cortical thickness for subjects from the ages of seven to nineteen, dividing the sample into three groups on the basis of their scores in the IQ tests: those of 'superior, 'high' and 'average' intelligence. IQ measures are normalized to the age group, and should in theory remain the same as the children age. Figure 2 on page 677 shows the curves for cortical thickness in brain areas that show different developmental patterns according to intelligence. Children in the group with superior intelligence have a thinner cortex in these areas in early childhood, but cortical thickness increases sharply until age eleven compared with the other groups, before decreasing through adolescence. The authors note that those of superior intelligence show a prolonged period of prefrontal cortical gain and the most rapid rate of change.

These differential changes do not occur in all cortical areas. The most notable positive correlations with IQ in late childhood occur in the prefrontal cortex. This region lies at the top of the information-processing hierarchy, receiving highly processed information from all five senses ${ }^{3}$. The brain areas showing the biggest difference in the shape of the growth curve between those with superior intelligence and the other groups lie in the lateral and medial frontal gyri. But are these the areas that are most active when subjects perform IQ tests? This aspect can be assessed by functional MRI, which provides an indirect measure of the increase in arterial blood flow to areas in which cellular activity is increased. Previously, subjects have been scanned while taking non-verbal tests that measure IQ, and increased activity has been found in the lateral and medial prefrontal cortex - regions that are among those highlighted by Shaw and colleagues' developmental measures ${ }^{4,5}$. Furthermore, individual differences in IQ are correlated with the amplitude of the functional MRI signal in the lateral prefrontal cortex ${ }^{6}$.

We know that variations in general intelligence, or $g$, among people depend to a great extent on genetic differences ${ }^{7}$. So, if $g$ is highly heritable and the increase in the thickness of the prefrontal cortex is related to $g$, it is tempting to assume that this developmental change in brain structure is determined by a person's genes. But one should be very wary of such a conclusion. The body's development is intimately linked to interactions with its environment. For example, in a classic experiment, Rosenzweig and Bennett ${ }^{8}$ showed that the thickness of the cortex in adult rats is affected by the degree to which the animals' early environment is enriched in terms of activities. Even in human adults, structural changes can be seen in the cortical grey matter as a result of practice ${ }^{9}$. Thus, it could be that people with superior intelligence also live in a richer social and linguistic environment, and that it is this that accounts for the sharp increase in the thickness of their prefrontal cortex in late childhood. However, Thompson and colleagues ${ }^{10}$ previously looked for genetic influences on brain structure by comparing the cortical thickness of pairs of identical and non-identical twins. They found that some regions, including the frontal cortex, are, to use their words, under "tight genetic control".

Shaw and colleagues speculate that differences in the shape of the growth curves of cortical thickness could be influenced by various factors. These include the number of neurons that collect in the subplate under the cortex during late fetal development, the development of the myelin sheath that insulates the fibres of the neurons, and the selective elimination at puberty of neuronal connections that are not useful. Testing these hypotheses will require animal experiments that measure cellular development. Studies in animals have the advantage that the relative influence of genetics and experience can be disentangled, and so should provide a clearer picture of how intellectual ability is affected by the factors that underpin cortical development.

Richard Passingham is in the Department of Experimental Psychology, University of Oxford, South Parks Road, Oxford OX13UD, UK. e-mail: dick.passingham@psy.ox.ac.uk

1. Shaw, P. et al. Nature $440,676-679$ (2006).

2. McDaniel, M. Intelligence 33, 337-346 (2005)

3. Passingham, R. E., Rowe, J. B. \& Sakai, K. in Attention in Action (eds Humphreys, G. W. \& Riddoch, M. J.) 263-286 (Psychology Press, Hove, 2005)

4. Duncan, J. et al. Science 289, 457-460 (2000).

5. Christoff, K. et al. Neurolmage 14, 1136-1149 (2001).

6. Gray, J. R., Chabris, C. F. \& Braver, T. S. Nature Neurosci. 6, 316-322 (2003).

7. Plomin, R. \& Spinath, F. M. Trends Cogn. Sci. 6, 169-176 (2002).

8. Rosenzweig, M. R. \& Bennett, E. L. Behav. Brain Res. 78, 57-65 (1996).

9. Draganski, B. et al. Nature 427, 311-312 (2004)

10. Thompson, P. M. et al. Nature Neurosci. 4, 1253-1258 (2001).

\section{ENVIRONMENTAL CHEMISTRY}

\section{Boiling up an acid plume}

There is more than just a sizzle when red-hot lava meets the sea. The plumes seen in this picture consist by the evaporation of water, but also of aerosols and gases that stem from the reaction between the lava and salt water.

M. Edmonds and T. M. Gerlach have investigated the composition of such plumes produced by lava from Kilauea Volcano, Hawaii (Earth Planet. Sci. Lett. doi:10.1016/j.epsl.2006.02. 005). Their main tool was open-path Fourier transform not only of steam produced infrared spectroscopy, which allowed remote sensing of the plumes and estimation of the amounts of various components - water, carbon dioxide, nitrogen dioxide, sulphur dioxide and hydrogen chloride. The most notable of Edmonds and Gerlach's conclusions stem from their analyses of this last species, $\mathrm{HCl}$.

First, from thermodynamic considerations they calculate that the $\mathrm{HCl}$ gas is created following the hydrolysis of magnesium chloride salts (and not of sodium chloride, as an alternative explanation has it). Second, given that conclusion, they estimate how much $\mathrm{HCl}$ is produced by the lava-seawater interaction. The outcome depends on various assumptions and factors, including the type, extent and duration of the lava flow.

Edmonds and Gerlach estimate that a lava flow of $1 \mathrm{~m}^{3} \mathrm{~s}^{-1}$ could in principle produce $3.7 \mathrm{~kg} \mathrm{~s}^{-1}$ of $\mathrm{HCl}$, or 300 tonnes daily. For various reasons that they discuss, this number is likely to be much lower (3-30 tonnes). Figures

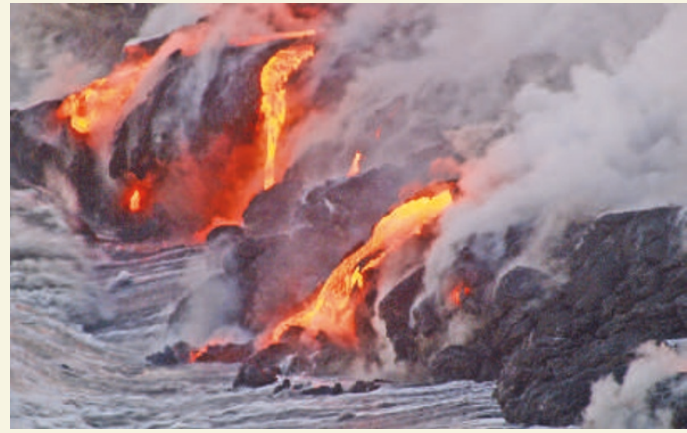

of this latter order of magnitude produce only localized high concentrations of $\mathrm{HCl}$ gas and acid rain. But the authors point out that in the past the story must have had a more serious edge. Eruptions of Hawaiian volcanoes in 1840, 1919 and 1950 produced massive lava flows, with sustained lava fluxes entering the sea. The result was an estimated $\mathrm{HCl}$ output of 200-2,200 tonnes per day over several weeks, a much more serious environmental hazard. Tim Lincoln 